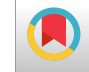

\title{
Prevalence and Factors Associated with Physical Punishment and Psychological Aggression Towards Children in Laos: Results of the 2017 Social Indicator Survey
}

\author{
Supa Pengpid ${ }^{1,2}$ and Karl Peltzer ${ }^{3,{ }^{*}}$ \\ ${ }^{1}$ ASEAN Institute for Health Development, Mahidol University, Salaya, Thailand \\ ${ }^{2}$ Department of Research Administration and Development, University of Limpopo, Turfloop, South Africa \\ ${ }^{3}$ Department of Psychology, University of the Free State, Bloemfontein, South Africa \\ "Corresponding author: Department of Psychology Room 202, Campus North Avenue, University of the Free State, Bloemfontein 9300, South Africa. Tel: +27-514012187, Email: \\ kpeltzer@hsrc.ac.za
}

Received 2019 September 01; Revised 2020 August 03; Accepted 2020 August 21.

\begin{abstract}
Background: Physical and psychological child punishment is an important public health problem.

Objectives: This study aimed to assess the prevalence and factors associated with physical punishment and psychological aggression toward children (1-14 years of age) in Laos.

Methods: In the nationally representative 2017 Lao Social Indicator Survey, 20,949 mothers or caretakers of children aged 1-14 years responded to questions on child disciplining methods used by adults in households during the past month and attitudes toward violence. Logistic regression was used to investigate the association between household and maternal characteristics and physical punishment and psychological aggression toward children.

Results: The prevalence of psychological aggression was 64.0\% (shouted, etc., 60.5\% and called child dumb, etc., 26.4\%), the prevalence of any physical punishment was 35.6\% (spanked, etc., $27.1 \%$, hit on extremities $23.9 \%$, hit on the bottom, etc., $4.9 \%$, hit on face $3.9 \%$, and "beat the child as hard as one could" $1.0 \%$ ). In adjusted logistic regression analysis, male gender, poorer household wealth status, living in the central and southern region of the country, the child living with biological parents, agreement with physical punishment of children were positively, while older age, urban residence, and belonging to the Lao-Tai ethnolinguistic group were negatively associated with any physical punishment. Older age, male gender, living in the central region of the country, the child living with biological parents, and agreement with physical punishment of children were positive, whereas rural residence without road and living in the southern region of the country were negatively associated with psychological aggression.

Conclusions: Psychological aggression and, to a lesser extent, physical punishment of children are common in Laos. Interventions to prevent psychological aggression and physical punishment towards children should support parents in adapting non-violent forms of parenting practices.
\end{abstract}

Keywords: Child Maltreatment, Laos, Violence

\section{Background}

"Child maltreatment is any form of physical and/or emotional or sexual abuse, deprivation and neglect of children, or commercial or other exploitation resulting in harm to the child's health, survival, development or dignity." (1) "Consequences of child maltreatment include impaired lifelong physical and mental health." $(1,2)$ "Parental corporal punishment was associated with all child constructs, including higher levels of immediate compliance and aggression and lower levels of moral internalization and mental health." (3) Three risk factors have been identified for physical child abuse, "parent anger/hyper- reactivity, family conflict, and family cohesion." (4)

Based on child abuse data collected from 28 developing and transitional countries, "a median of $83 \%, 64 \%$, and $43 \%$ of children in the African region experienced psychological and moderate and severe physical abuse, respectively, and in transitional countries, children experienced these forms of abuse (56\%, 46\%, and 9\%, respectively)." (5) Severe physical punishment in Southeast Asia was $24.6 \%$ in Bangladesh ( 1 - 14 years) in 2012/13, 7.6\% in Laos ( 2 - 14 years) in $2011 / 12,14.0 \%$ in Nepal ( 1 - 14 years) in 2014 and $2.1 \%$ in Vietnam (1 - 14 years) in 2014 (6). In Vietnam, 55.0\% of children ( 2 - 14 years) had been physically punished, and 55.4\% had experienced psychological aggression (7). In Nepal, 
the prevalence of physical punishment among children (3 - 14 years) was $45.8 \%$ (8), and among children of 1 - 14 years, 77.3\% experienced emotional abuse in Nepal (9). In Vietnam, $17.3 \%$ (7), and in Nepal, 35.2\% (8) of mothers or caretakers endorsed the need for corporal punishment for children. In Laos, corporal punishment "prohibition is still to be achieved in the home, alternative care, settings, daycare, and penal institutions." (10)

In the Laos "Violence against Children Survey",16.0\% of children ( $<18$ years) had experienced any physical violence by anybody (parents, peers, any adult, intimate partner) during their childhood and 7.4\% in the past year, and $21.1 \%$ of children had experienced emotional abuse during their childhood, and 9.8\% in the past year by a "parent, guardian, adult caregiver or other adult relatives" (11). There is a lack of information about the prevalence and factors associated with physical punishment and psychological aggression toward children (1-14 years) in Laos.

Factors associated with physical punishment of children may include age ( 5 - 9 years (7), decreases with age (8)), boys $(5,7,8)$, living in poorer households $(5,7,12)$, higher household size (5), lower education of adults in households (7), living with (both) biological parents (7), ethnicity (8), residing in rural areas (7), and positive attitudes toward corporal punishment $(5,7,8,13)$. Factors associated with psychological aggression against children may include being female (9), being male (5), poorer wealth status $(5,9)$, larger household size (5), lower education of household head (9), and ecological region (9).

\section{Objectives}

The present study aimed to assess the prevalence and factors associated with physical punishment and psychological aggression toward children ( 1 - 14 years of age) in Laos.

\section{Methods}

\subsection{Sample and Procedure}

The study utilized the cross-sectional sample of the "2017 Lao Social Indicator Survey" designed to "provide estimates for a large number of indicators on the situation of children and women at the national level." (14) "The urban and rural areas within each province were identified as the main sampling strata, and the sample population of households was selected in two stages." (14) "Within each stratum, a specified number of census enumeration areas were selected systematically with probability proportional to size. After a household listing was carried out within the selected enumeration areas, a systematic sample of
20 households was drawn from each sample enumeration area." (14)The child discipline module was implemented in all households with at least one child between 1 - 14 years. If the household had more than one child between 1 - 14 years old, one child was randomly selected using the Kish method (14). Interviews were conducted using "ComputerAssisted Personal Interviewing (CAPI)". The response rate was more than $96 \%$ of mothers or caretakers with a child 1 - 14 years $(N=20,949)$ (14). "The survey protocol was approved by Lao Statistics Bureau (LSB) in May 2016.” (14) Informed consent was obtained from adults participating in the survey (14).

To determine the minimum number of subjects for adequate study power (https://clincalc.com/stats/samplesize.aspx) in population surveys with dichotomous, 95\% power and alpha .05, the prevalence of child punishment was 33\% in Nepal (8) and $35 \%$ in this study, and the minimum sample size is 7,277 . Since this study is analyzed secondary data, we used all 20,949 data records.

\subsection{Measures}

A modified version of the "Parent-Child Conflict Tactics Scale" (PCCTS) (15) was used to assess 11 child discipline behaviors (Table 1 ) by any household member on one child 1 - 14 years in the past month (14). Attitude towards physical punishment were assessed with the question of "Do you believe that in order to bring up, raise, or educate a child properly, the child needs to be physically punished?" (14) The reliability of scores from the PCCTS was 0.71 in the current study. A household questionnaire was utilized to collect demographic information, including household wealth (14).

\subsection{Data Analysis}

Data analysis was done with "STATA software version 15.0 (Stata Corporation, College Station, Texas, USA)”, by taking the complex study design into account. The results were described with descriptive statistics, and logistic regression was used to identify the independent contribution of socio-demographic and maternal variables to physical punishment and psychological aggression, separately. $\mathrm{P}<0.05$ was considered significant.

\section{Results}

The prevalence of psychological aggression was 64.0\% (shouted, etc. 60.5\% and called child dumb, etc., 26.4\%), the prevalence of any physical punishment was $35.6 \%$ (spanked, etc. 27.1\%, hit on extremities $23.9 \%$, hit on the bottom, etc. $4.9 \%$, hit or slapped on face $3.9 \%$, and beat the child 


\begin{tabular}{|c|c|}
\hline Disciplinary Method & $\%$ (95\% Confidence Interval) \\
\hline \multicolumn{2}{|l|}{ Non-violent discipline } \\
\hline 1. "Explained why (name)'s behavior was wrong." & $82.5(81.8,83.2)$ \\
\hline 2. "Took away privileges, forbade something (name) liked, or did not allow (him/her) to leave the house." & $55.5(54.6,56.4)$ \\
\hline 3. "Gave (him/her) something else to do." & $19.7(19.0,20.4)$ \\
\hline Non-violent discipline only & $24.6(23.9,25.3)$ \\
\hline Psychological aggression (items 4 - 5) & $64.0(63.2,64.8)$ \\
\hline 4. "Shouted, yelled at, or screamed at (him/her)." & $60.5(60.0,61.3)$ \\
\hline 5. "Called (him/her) dumb, lazy, or other names like that." & $26.4(25.7,27.2)$ \\
\hline Physical punishment (items 6 - 11) & $35.6(34.8,36.4)$ \\
\hline 6. "Spanked, hit, or slapped (him/her) on the bottom with bare hand." & $27.1(26.3,27.9)$ \\
\hline 7. "Hit or slapped (him/her) on the hand, arm, or leg." & $23.9(23.2,24.7)$ \\
\hline 8. Shook (him/her)." & $6.5(6.1,6.9)$ \\
\hline 9. "Hit (him/her) on the bottom or elsewhere on the body with something like a belt, hairbrush, stick, or other hard objects." & $4.9(4.6,5.3)$ \\
\hline 10. "Hit or slapped (him/her) on the face, head or ears". & $3.9(3.7,4.3)$ \\
\hline 11. "Beat (him/her) up that is hit (him/her) over and over as hard as one could." & $1.0(0.8,1.1)$ \\
\hline Severe physical punishment (items 9 - 11) & $8.0(7.6,8.5)$ \\
\hline
\end{tabular}

as hard as one could 1.0\%), and those who used non-violent discipline only were $24.6 \%$ (Table 1 ).

\subsection{Physical Punishment}

In adjusted logistic regression analysis, male sex, poorer household wealth status, living in the central and southern region of the country, the child living with biological parents, and agreement with physical punishment of children were positively, while older age, urban residence, and being a member of the Lao-Tai ethnolinguistic group were negatively associated with any physical punishment (Table 2).

\subsection{Psychological Aggression}

In adjusted logistic regression analysis, older age, male sex, living in the central region of the country, the child living with biological parents, and agreement with physical punishment of children were positively, whereas rural residence without road, and living in the southern region of the country were negatively associated with psychological aggression (Table 3).

\section{Discussion}

The study found a prevalence of psychological aggression of $64.0 \%$; any physical punishment was $35.6 \%$, and severe physical punishment $8.0 \%$. A previous multi-country study found higher rates for the Africa region and similar rates for transitional countries (5). The prevalence of severe physical punishment was similar to the 2011/12 Laos survey (2 - 14 years) (7.6\%), lower than in Bangladesh (1 - 14 years) (24.6\%), and Nepal (1 - 14 years) (14.0\%) and higher than in Vietnam (1 - 14 years) (2.1\%) (6). The prevalence of any physical punishment was lower in this study than in Nepal (3 - 14 years) (45.8\%) (8), and Vietnam (2 - 14 years) (55.0\%) (7). The prevalence of psychological aggression in this study was higher than in Vietnam (2 - 14 years) $(55.4 \%)$ (7), while lower than in Nepal (77.3\%) (9). The prevalence of positive attitudes toward corporal punishment of children in this study was higher than in Vietnam (17.3\%) (7), and lower than in Nepal (35.2\%) (8). The study found some discrepancy between agreeing with corporal punishment (25.8\%) and the actual prevalence of past-month physical violence of children (35.6\%). Similar discrepancies have been found in previous studies (7). Corporal punishment is still not prohibited in the home in Laos (10). In 2011, the "United Nations Committee on the Rights of the Child" recommended to the Lao government to, among others, "Prohibit all forms of corporal punishment of children in all settings and promote the use of alternative forms of discipline." (11) In 2015, the Lao government passed a new "Law on Preventing and Combatting Violence against Women and Violence against Children", which "prohibits physical, emotional, sexual, and economic violence against women and children in all settings." (11)

Consistent with previous studies $(5,7,8)$, this study 


\begin{tabular}{|c|c|c|c|}
\hline Variable & $\%$ & Unadjusted Odds Ratio (95\% CI) & Adjusted Odds Ratio (95\% CI) \\
\hline \multicolumn{4}{|l|}{ Age in years } \\
\hline $1-4$ & 43.2 & 1 (Reference) & 1 (Reference) \\
\hline $5-9$ & 30 & $0.87(0.81,0.93)^{\mathrm{a}}$ & $0.78(0.71,0.85)^{\mathrm{a}}$ \\
\hline $10-14$ & 26.8 & $0.28(0.25,0.30)^{\mathrm{a}}$ & $0.25(0.22,0.27)^{\mathrm{a}}$ \\
\hline \multicolumn{4}{|l|}{ Sex } \\
\hline Female & 49.1 & 1 (Reference) & 1 (Reference) \\
\hline Male & 50.9 & $1.24(1.17,1.33)^{\mathrm{a}}$ & $1.24(1.16,1.33)^{\mathrm{a}}$ \\
\hline \multicolumn{4}{|l|}{ Mother's education } \\
\hline Lower secondary or more & 34.2 & 1 (Reference) & 1 (Reference) \\
\hline Primary or less & 65.8 & $0.98(0.91,1.06)$ & $1.04(0.95,1.19)$ \\
\hline \multicolumn{4}{|l|}{ Wealth } \\
\hline Fourth/Richest & 36.1 & 1 (Reference) & 1 (Reference) \\
\hline Poorest/Second/Middle & 63.9 & $1.21(1.12,1.30)^{\mathrm{a}}$ & $1.31(1.18,1.48)^{\mathrm{a}}$ \\
\hline \multicolumn{4}{|l|}{ Number of household members } \\
\hline $1-4$ & 33.2 & 1 (Reference) & 1 (Reference) \\
\hline $5-6$ & 39.5 & $1.15(1.06,1.25)^{\mathrm{a}}$ & $1.07(0.98,1.17)$ \\
\hline 7 or more & 27.3 & $1.22(1.11,1.34)^{\mathrm{a}}$ & $1.02(0.92,1.16)$ \\
\hline \multicolumn{4}{|l|}{ Residence } \\
\hline Urban & 27.9 & 1 (Reference) & 1 (Reference) \\
\hline Rural with road & 60.8 & $1.01(0.93,1.10)$ & $0.88(0.80,0.96)^{b}$ \\
\hline Rural without road & 11.3 & $0.84(0.74,0.95)^{\mathrm{b}}$ & $0.71(0.61,0.82)^{\mathrm{a}}$ \\
\hline \multicolumn{4}{|l|}{ Region } \\
\hline North & 31.9 & 1 (Reference) & 1 (Reference) \\
\hline Central & 48.1 & $1.31(1.22,1.42)^{\mathrm{a}}$ & $1.43(1.31,1.54)^{\mathrm{a}}$ \\
\hline South & 20 & $1.11(1.01,1.22)^{\mathrm{c}}$ & $1.15(1.03,1.27)^{\mathrm{b}}$ \\
\hline \multicolumn{4}{|l|}{ Ethnolinguistic group } \\
\hline Other & 40.6 & 1 (Reference) & 1 (Reference) \\
\hline Lao-Tai & 59.4 & $0.87(0.81,0.93)^{\mathrm{a}}$ & $0.91(0.83,0.99)^{\mathrm{c}}$ \\
\hline \multicolumn{4}{|l|}{ Child living status } \\
\hline Child lives with neither parent & 7.5 & 1 (Reference) & 1 (Reference) \\
\hline Child lives with either parent & 8.3 & $1.41(1.17,1.70)^{\mathrm{a}}$ & $1.31(1.08,1.56)^{b}$ \\
\hline Child lives with both parents & 84.2 & $1.29(1.11,1.49)^{\mathrm{a}}$ & $1.22(1.05,1.46)^{b}$ \\
\hline \multicolumn{4}{|l|}{ Agree with physical punishment } \\
\hline No & 74.2 & 1 (Reference) & 1 (Reference) \\
\hline Yes & 25.8 & $2.26(2.08,2.46)^{\mathrm{a}}$ & $2.55(2.33,2.80)^{\mathrm{a}}$ \\
\hline
\end{tabular}

Abbreviation: $\mathrm{CI}$, confidence interval

${ }^{\mathrm{a}} \mathrm{P}<0.001$

${ }^{\mathrm{b}} \mathrm{P}<0.01$

${ }^{c} \mathrm{P}<0.05$ 


\begin{tabular}{|c|c|c|}
\hline Variable & Unadjusted Odds Ratio (95\% CI) & Adjusted Odds Ratio (95\% CI) \\
\hline \multicolumn{3}{|l|}{ Age in years } \\
\hline $1-4$ & 1 (Reference) & 1 (Reference) \\
\hline 5-9 & $1.76(1.64,1.90)^{\mathrm{a}}$ & $1.66(1.53,1.83)^{a}$ \\
\hline $10-14$ & $1.29(1.19,1.39)^{\mathrm{a}}$ & $1.25(1.14,1.37)^{\mathrm{a}}$ \\
\hline \multicolumn{3}{|l|}{ Sex } \\
\hline Female & 1 (Reference) & 1 (Reference) \\
\hline Male & $1.11(1.04,1.18)^{a}$ & $1.13(1.05,1.22)^{\mathrm{b}}$ \\
\hline \multicolumn{3}{|l|}{ Mother's education } \\
\hline Lower secondary or more & 1 (Reference) & 1 (Reference) \\
\hline Primary or less & $1.07(0.99,1.19)$ & $0.91(0.82,1.00)$ \\
\hline \multicolumn{3}{|l|}{ Wealth } \\
\hline Fourth/Richest & 1 (Reference) & 1 (Reference) \\
\hline Poorest/Second/Middle & $1.13(1.05,1.22)^{\mathrm{a}}$ & $1.09(0.98,1.21)$ \\
\hline \multicolumn{3}{|l|}{ Number of household members } \\
\hline $1-4$ & 1 (Reference) & 1 (Reference) \\
\hline 5-6 & $1.09(1.00,1.18)^{\mathrm{c}}$ & $1.10(1.00,1.20)$ \\
\hline 7 or more & $0.98(0.89,1.07)$ & $0.98(0.88,1.09)$ \\
\hline \multicolumn{3}{|l|}{ Residence } \\
\hline Urban & 1 (Reference) & 1 (Reference) \\
\hline Rural with road & $1.12(1.05,1.23)^{\mathrm{b}}$ & $1.08(0.97,1.19)$ \\
\hline Rural without road & $0.88(0.78,0.99)^{c}$ & $0.82(0.71,0.96)^{c}$ \\
\hline \multicolumn{3}{|l|}{ Region } \\
\hline North & 1 (Reference) & 1 (Reference) \\
\hline Central & $1.13(1.04,1.22)^{b}$ & $1.20(1.09,1.32)^{a}$ \\
\hline South & $0.70(0.64,0.77)^{\mathrm{a}}$ & $0.75(0.68,0.84)^{\mathrm{a}}$ \\
\hline \multicolumn{3}{|l|}{ Ethnolinguistic group } \\
\hline Other & 1 (Reference) & 1 (Reference) \\
\hline Lao-Tai & $0.80(0.75,0.86)^{\mathrm{a}}$ & $0.92(0.83,1.01)$ \\
\hline \multicolumn{3}{|l|}{ Child living status } \\
\hline Child lives with neither parent & 1 (Reference) & 1 (Reference) \\
\hline Child lives with either parent & $1.17(0.98,1.40)$ & $1.15(0.95,1.40)$ \\
\hline Child lives with both parents & $1.26(1.10,1.44)^{a}$ & $1.21(1.04,1.40)^{\mathrm{c}}$ \\
\hline \multicolumn{3}{|l|}{ Agree with physical punishment } \\
\hline No & 1 (Reference) & 1 (Reference) \\
\hline Yes & $2.64(2.40,2.90)^{\mathrm{a}}$ & $2.42(2.19,2.66)^{\mathrm{a}}$ \\
\hline
\end{tabular}

Abbreviation: CI, confidence interval

${ }^{\mathrm{a}} \mathrm{P}<0.001$

${ }^{\mathrm{b}} \mathrm{P}<0.01$

${ }^{\mathrm{c}} \mathrm{P}<0.05$ 
found that the prevalence of physical violence and psychological aggression was higher in boys than in girls. Possible reasons for this may be "higher expectations of male children" (8). Physical violence decreased with age, which was found previously (8), and psychological aggression increased with age in this study. This result may be explained with body-mind development from pre-school to early adolescent age.

In agreement with previous investigations $(5,7,12)$, this study found that the prevalence of physical punishment and psychological aggression was in adjusted and/or bivariate analysis higher among children living in poorer households, and having a greater number of household members. It is possible that mothers or caretakers from poorer households have more economic and resource shortage stresses, which may, in turn, increase violent disciplining behavior. Although in a previous study in Vietnam (7), residing in rural areas was associated with physical punishment, this study found that rural residence decreased the odds of physical punishment and psychological aggression. More research is needed to investigate these rural-urban differences.

As found previously $(5,7,8,13)$, positive attitudes toward corporal punishment increased the odds of physical punishment and psychological aggression. Some previous studies $(7,9)$ found an association between lower education of household members or household head with physical punishment and psychological aggression against children; however, this study did not find such an association. Consistent with a previous study (7), living with (both) biological parents increased the odds of physical punishment and psychological aggression. Additional qualitative studies may be needed to explain this finding.

Being a Lao-Tai decreased the odds of physical punishment in this study. Ethnic differences in the prevalence of physical punishment were also found in a study in Nepal (8). "Among the different ethnolinguistic groups in Laos, the Lao-Tai have the highest educational levels and lowest poverty rates," (16) which may explain the lower prevalence of physical punishment of children among the LaoTai. Compared to the northern region in Laos, the central region had a higher prevalence of physical punishment and psychological aggression, while the southern region had higher odds of physical punishment and lower odds of psychological aggression. Differences in the prevalence of child maltreatment by ecological regions have been found previously (9).

\subsection{Study Limitations}

The study had a limitation of cross-sectional design. The variables reported here were assessed by self-report, which might have bias. Recall period of child discipline behaviors was limited to the past one month, which may have reduced recall bias. The selection of variables included in this study was limited to the pre-existing MICS modules.

\subsection{Conclusion}

Psychological aggression and physical punishment of children are common in Laos. Several factors for physical punishment and/or psychological aggression were identified, such as male sex, age, poorer economic background, urban residence, non-Lao-Tai ethnolinguistic groups, and endorsing physical punishment attitudes. Interventions to prevent psychological aggression and physical punishment of children should support parents in adapting nonviolent forms of parenting practices.

\section{Footnotes}

Authors' Contribution: Supa Pengpid and Karl Peltzer designed the study, analyzed the data, and wrote the manuscript. All authors read and approved the final version of the manuscript.

Conflict of Interests: The authors declare no conflict of interest.

Ethical Approval: The survey protocol was approved by Lao Statistics Bureau (LSB) in May 2016." Informed consent was obtained from adults participating in the survey.

Funding/Support: The study did not receive funding.

Informed Consent: Informed consent was obtained from adults participating in the survey.

\section{References}

1. World Health Organization (WHO). Child maltreatment. 2018, [cited 22 July 2019]. Available from: https://www.who.int/news-room/factsheets/detail/child-maltreatment.

2. Gilbert R, Widom CS, Browne K, Fergusson D, Webb E, Janson S. Burden and consequences of child maltreatment in high-income countries. Lancet. 2009;373(9657):68-81. doi: 10.1016/s0140-6736(08)61706-7.

3. Gershoff ET. Corporal punishment by parents and associated child behaviors and experiences: a meta-analytic and theoretical review. Psychol Bull. 2002;128(4):539-79. doi: 10.1037/0033-2909.128.4.539. [PubMed: 12081081].

4. Stith SM, Liu T, Davies L, Boykin EL, Alder MC, Harris JM, et al. Risk factors in child maltreatment: A meta-analytic review of the literature. Aggression Violent Behav. 2009;14(1):13-29. doi: 10.1016/j.avb.2006.03.006.

5. Akmatov MK. Child abuse in 28 developing and transitional countries-results from the Multiple Indicator Cluster Surveys. Int J Epidemiol. 2011;40(1):219-27. doi: 10.1093/ije/dyq168. [PubMed: 20943933].

6. Klevens J, Ports KA. Gender Inequity Associated with Increased Child Physical Abuse and Neglect: a Cross-Country Analysis of Population-Based Surveys and Country-Level Statistics. J Fam Violence. 2017;32(8):799-806. doi: 10.1007/s10896-017-9925-4. [PubMed: 29599571]. [PubMed Central: PMC5868418]. 
7. Cappa C, Dam H. Prevalence of and risk factors for violent disciplinary practices at home in Viet Nam. J Interpers Violence. 2014;29(3):497-516. doi: 10.1177/0886260513505215. [PubMed: 24162756].

8. Kandel P, Kunwar R, Karki S, Kandel D, Lamichhane P. Child maltreatment in Nepal: prevalence and associated factors. Public Health. 2017;151:106-13. doi: 10.1016/j.puhe.2017.06.020. [PubMed: 28763786].

9. Atteraya MS, Ebrahim NB, Gnawali S. Determinants of child maltreatment in Nepal: Results from the 2014 Nepal multiple indicator cluster survey (the 2014 NMICS). Child Abuse Negl. 2018;76:400-7. doi: 10.1016/j.chiabu.2017.11.018. [PubMed: 29232623].

10. Global Initiative to End All Corporal Punishment of Children. Country Report for Lao People's Democratic Republic. 2018, [cited 22 July 2019]. Available from: https://endcorporalpunishment.org/reportson-every-state-and-territory/lao-pdr/.

11. National Commission for Mothers and Children Lao Statistics Bureau and UNICEF Lao PDR. National Violence against Children Survey in Lao PDR. Preliminary Report. Lao PDR: NCMC; 2016.

12. Choi S, Yoo J, Park J, Lee HY, Tran HTG, Lee JK, et al. Manifestations of socioeconomic status and its association with physical child punishment- Results from the Multi-Indicators Cluster
Survey in Viet Nam, 2006-2014. Child Abuse Negl. 2018;85:1-8. doi: 10.1016/j.chiabu.2018.08.022. [PubMed: 30201520]. [PubMed Central: PMC6476300].

13. Cappa C, Khan SM. Understanding caregivers' attitudes towards physical punishment of children: evidence from 34 low- and middle-income countries. Child Abuse Negl. 2011;35(12):1009-21. doi: 10.1016/j.chiabu.2011.10.003. [PubMed: 22152701].

14. Lao Statistics Bureau. Lao Social Indicator Survey II 2017, Survey Findings Report. Vientiane, Lao PDR: Lao Statistics Bureau and UNICEF; 2018.

15. Straus MA, Hamby SL, Finkelhor D, Moore DW, Runyan D. Identification of Child Maltreatment With the Parent-Child Conflict Tactics Scales: Development and Psychometric Data for a National Sample of American Parents. Child Abuse Neglect. 1998;22(4):249-70. doi: 10.1016/s0145-2134(97)00174-9.

16. The United Nations in Lao PDR. Country analysis report: Lao PDR analysis to inform the Lao People's Democratic Republic-United Nations Partnership Framework (2017-2021). 2015, [cited 22 June 2019]. Available from: http://www.la.undp.org/content/lao_pdr/en/home/ library/mdg/country-analysis-report.html. 